\title{
Indirubin suppresses ovarian cancer cell viabilities through the STAT3 signaling pathway
}

This article was published in the following Dove Press journal:

Drug Design, Development and Therapy

\section{Lihong Chen \\ Jinhua Wang \\ Jianbo Wu \\ Qiaomei Zheng \\ Jifen $\mathrm{Hu}$}

Department of Obstetrics and Gynecology, The First Affiliated

Hospital of Fujian Medical

University, Fuzhou, China
Correspondence: Jifen $\mathrm{Hu}$ Department of Obstetrics and Gynecology, The First Affiliated Hospital of Fujian Medical University, No 20 Chazhong Road, Fuzhou, Fujian, 350005, China

$\mathrm{Tel} / \mathrm{fax}+86059187983333$

Email jifenhu_fi@।26.com
Background: Indirubin is the active component of Danggui Longhui Wan, a traditional Chinese medicine formulation. Due to its anti-inflammation and anti-tumor effects, indirubin has been widely used for the treatment of inflammation, cancer, and other chronic disease. Herein, we aimed to investigate the role and mechanism of indirubin in human ovarian cancer cell proliferation.

Materials and methods: The cell viability was determined by Cell Counting Kit- 8 and colony formation assays by treatment with different dosages of indirubin over 72 hours. Apoptosis was examined by flow cytometry with fluorescein isothiocyanate Annexin V Apoptosis Detection Kit. Western blot assay was finally applied to analyze the expression of cancer-related STAT3 pathway and its downstream proteins.

Results: Indirubin was found to significantly inhibit cell viability and induce apoptosis in 2 human ovarian cancer cell lines. Mechanistic studies revealed that indirubin treatment led to reduced levels of phosphorylated-STAT3, thus repressing the downstream pro-survival proteins and elevating pro-apoptosis ones.

Conclusion: Our study provided the evidence for anti-survival activity of indirubin by inhibiting cell viability and inducing apoptosis in human ovarian cancer cells, which involved impaired STAT3 signaling pathway. Our findings further support indirubin as a potential drug candidate against human ovarian cancer.

Keywords: indirubin, ovarian cancer, cell viability, STAT3 signaling

\section{Introduction}

Ovarian cancer is the most common and second lethal type of gynecological cancer affecting women worldwide. ${ }^{1,2}$ Due to lack of evident symptoms, most of patients with ovarian cancer are diagnosed at the advanced stage, leading to a 5-year survival rate ranging from $25 \%$ to $30 \% .{ }^{3}$ Besides, high recurrence rate and chemo-resistance also contribute to poor prognosis and high mortality among these patients. ${ }^{4,5}$ Therefore, a refined investigation of the therapy strategies and identification of novel agents for ovarian cancer, especially high-grade ovarian cancer, are urgently required to improve the survival rate of this disease.

Till now, numerous natural products (mostly plant extracts) have been used to treat human diseases, including cancers. ${ }^{6,7}$ They constitute the basis for multiple prescriptions in traditional Chinese medicine and appear as a complementary approach to treat cancers. ${ }^{8}$ Danggui Longhui Wan is a compound from traditional Chinese medicine consisting of 11 herbal medicines, and is used for treating chronic myeloid leukemia. ${ }^{9}$ Among the 11 medicinal ingredients, Qing Dai (indigo naturalis) appears to be closely associated with the anti-leukemic activity, which is composed of high levels of indigo dye and a minor but active component indirubin. It has been discovered that 
indirubin and its derivatives are strong inhibitors of cyclindependent kinases (CDKs) by competing with ATP binding at the catalytic site, resulting in G2/M arrest and apoptosis in cancer cells. ${ }^{10,11}$ Indirubin derivative has been proved to inhibit tumor cell growth in many types of cancer cell lines and induced apoptosis. ${ }^{12}$ Indirubin derivative E738 has been identified as a novel dual inhibitor of JAKs and SFKs, which leads to inhibition of STAT3 signaling. ${ }^{13}$ And indirubin derivative $6 \mathrm{BIO}$ has been reported to exert the unique property of increasing stress tolerance and, in parallel, partially suppressing the nutrient-sensing pathway signaling. ${ }^{14}$ Moreover, indirubin has been reported to decrease the susceptibility to influenza virus and promote the expression of interferon- $\beta$ and interferon-inducible transmembrane 3 through promoting mitochondrial antiviral signaling pathway. ${ }^{15}$ Over the last 2 decades, numerous studies relevant to anti-tumor activity of indirubin have been reported in the literature. However, whether it possesses oncotherapy potential in ovarian cancer remains unclear.

In this study, we focus our work on investigating the effect of simple indirubin on cell survival, including cell proliferation and apoptosis, in 2 different ovarian cancer cell lines and elucidate the significant cytotoxic mechanisms of this compound against ovarian cancer cells.

\section{Materials and methods}

This work was approved by the review board of The First Affiliated Hospital of Fujian Medical University.

\section{Cell culture and reagent}

Human cervical cancer cell lines A2780 and OVCAR3 were purchased from the cell bank of Shanghai Institute of Biochemistry and Cell Biology (Shanghai, China). The cells were cultured in Roswell Park Memorial Institute 1640 medium with $10 \%$ fetal bovine serum (Thermo Fisher Scientific, Waltham, MA, USA), $100 \mathrm{U} / \mathrm{mL}$ of penicillin and $100 \mu \mathrm{g} / \mathrm{mL}$ of streptomycin (Thermo Fisher Scientific) in a $5 \% \mathrm{CO}_{2}$ incubator at $37^{\circ} \mathrm{C}$. Indirubin was purchased from Sigma-Aldrich (San Francisco, CA, USA). Colivelin was purchased from Santa Cruz Biotechnology (sc-361153, Santa Cruz, CA, USA).

\section{Cell Counting Kit-8 (CCK-8) assay}

Cell viability assay was performed by CCK- 8 methods. Briefly, cells were seeded in 96-well plate overnight at a density of $2 \times 10^{3}$ per well, and then treated with different concentrations of indirubin ( 2 and $5 \mu \mathrm{M}$ ) for $0,24,48$, or 72 hours, respectively. After incubation, $10 \mu \mathrm{L}$ Cell Counting Kit-8 (Dojindo, Tokyo, Japan) was added into each well for 1 hour. The OD of each sample was detected at $450 \mathrm{~nm}$ using a microplate reader. The experiments were performed in triplicate.

\section{Colony formation assay}

Cell viability assay was performed by colony formation assay and crystal violet staining methods. Briefly, the cells were seeded into a 6 -well plate at $5 \times 10^{3}$ per well. After 12 hours, the cells were treated with indirubin at the concentration of $5 \mu \mathrm{M}$ at $37^{\circ} \mathrm{C}$. The culture medium was refreshed every 2 days. Ten days later, the cells were washed twice with PBS and fixed in 4\% paraformaldehyde for 30 minutes. After washing twice with PBS buffer, the cells were stained with $1 \%$ crystal violet staining buffer for 30 minutes. The plates were then aspirated, washed, and allowed to air dry, followed by photograph by digital camera.

\section{Flow cytometry analysis}

Cell apoptosis assay was conducted by flow cytometry with fluorescein isothiocyanate (FITC) Annexin V Apoptosis Detection Kit (BD Biosciences, San Jose, CA, USA) as per the manufacturer's protocol. Briefly, the cells were treated with different concentrations of indirubin $(0,0.5$, $1,2,5,10$, and $20 \mu \mathrm{M}$ ) for 72 hours, followed by harvesting and suspending in binding buffer at a concentration of $1.5 \times 10^{6}$ cells $/ \mathrm{mL}$. Then, $5 \mu \mathrm{L}$ FITC Annexin V and $5 \mu \mathrm{L}$ propidium iodide staining solution were added to $200 \mu \mathrm{L}$ of the cell suspension. The mixture was incubated for 30 minutes at room temperature in dark and cells apoptosis was detected by BD FACSVerse ${ }^{\mathrm{TM}}$ (BD Biosciences). Apoptosis rate of cancer cells were analyzed by BD FACSuite software.

\section{Western blot assay}

A2780 and OVCAR3 cells were treated with different concentrations of indirubin ( 2 and $5 \mu \mathrm{M}$ ) or pretreated with $0.5 \mu \mathrm{M}$ colivelin. Forty-eight hours later, the cells were washed by PBS and harvested by RIPA buffer (Beyotime, Shanghai, China) with $1 \mathrm{mM}$ phenylmethylsulfonyl fluoride (Beyotime) on ice for 30 minutes. After centrifuging at $13,000 \mathrm{~g}$ at $4^{\circ} \mathrm{C}$ for 15 minutes, the supernatant fractions were collected and the protein concentration was quantified using a BCA Protein Assay Kit (Beyotime). The remaining supernatant was mixed with $2 \times$ loading buffer and boiled at $100^{\circ} \mathrm{C}$ for 15 minutes. The same amounts of protein were separated using $12 \%$ sodium dodecyl sulfate polyacrylamide gel electrophoresis and then transferred to nitrocellulose membrane (Millipore, Billerica, MA, USA). After transferring, the membrane was blocked with 5\% fat-free milk in PBST (PBS with Tween 20). Primary antibodies were incubated at $4^{\circ} \mathrm{C}$ overnight, and secondary antibodies were incubated at room temperature for 1 hour. The membranes 
were washed in PBST and the proteins of interest were visualized using enhanced chemiluminescence Western blotting substrate (Pierce, Rockford, IL, USA). $\beta$-actin was used as an internal control. Anti-p-STAT (Tyr705) (1:1,000, \#9145), anti-t-STAT3 (1:1,000,\#9139), anti-Bcl-xL (1:1,000,\#2764), anti-bax (1:1,000, \#2774), anti-cleaved caspase 3 (1:1,000, \#9664), and anti- $\beta$-actin (1:5,000, \#3700) antibodies were from Cell Signaling Technology (San Jose, CA, USA). AntiCyclin D1 (1:1,000, sc-450) and anti-C-myc (1:1,000, sc-4084) antibodies were from Santa Cruz (Dallas, TX, USA).

\section{Statistical analysis}

All data were analyzed by GraphPad Prism 7.0 software. Comparison between groups was performed by one-way ANOVA followed by Student-Newman-Keuls test. The data were presented as mean $\pm \mathrm{SD}$. A $P$-value $<0.05$ was considered as statistically significant. All experiments were repeated thrice independently.

\section{Results}

\section{Indirubin inhibits cell viability of human ovarian cancer cells}

To characterize the cytotoxicity of indirubin on human ovarian cancer cells, we first treated 2 different ovarian cancer cell lines, A2780 and OVCAR3, with increasing dosages of indirubin $(0,0.5,1,2,5,10$, and $20 \mu \mathrm{M})$ for 72 hours. Then cell viability was analyzed by CCK- 8 assay. The results shown in Figure 1A revealed a similarly decreased cell viability following treatment with indirubin at $>2 \mu \mathrm{M}$ concentrations. And the half maximal inhibitory concentration value of indirubin for each cell line was $\sim 4 \mu \mathrm{M}$. By treating the 2 cell lines with either 2 or $5 \mu \mathrm{M}$ indirubin for 3 days continuously, we observed a similar time-dependent inhibition of cell viability, and that $5 \mu \mathrm{M}$ indirubin made the faster suppression (Figure 1B and C). In addition, treatment with $5 \mu \mathrm{M}$ indirubin significantly inhibited colony formation in both A2780 and OVCAR3 cell lines (Figure 1D). These results indicate that indirubin represses cell viability of ovarian cancer cells in vitro.

\section{Indirubin induces apoptosis of human ovarian cancer cells}

To examine whether indirubin represses cell viability via inducing cell apoptosis in the 2 ovarian cancer cell lines tested, we then evaluated the apoptosis rate of indirubintreated cells through flow cytometry with FITC Annexin V Apoptosis Detection Kit. As shown in Figure 2A-C, after incubation with increasing concentrations of indirubin $(0,0.5$,
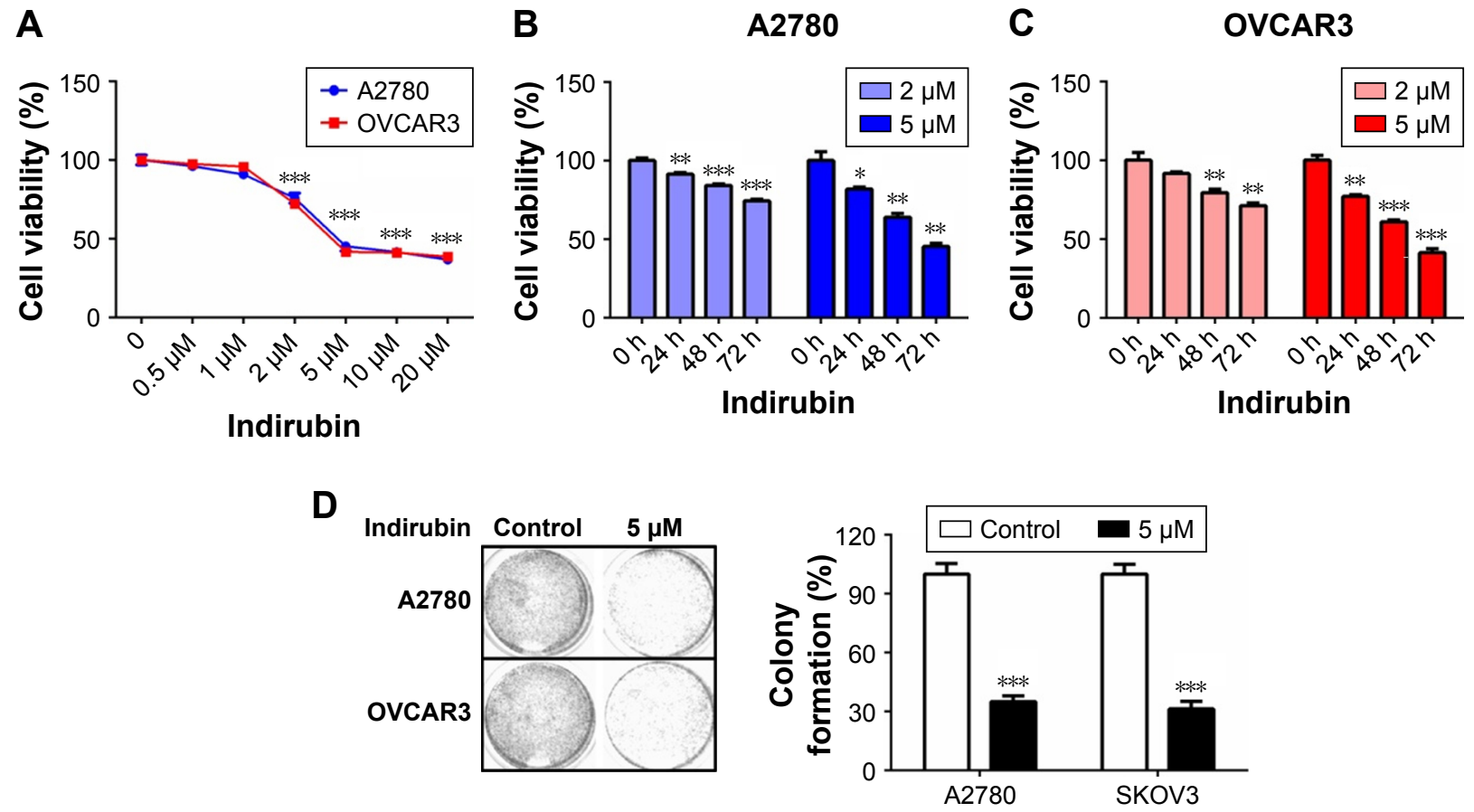

Figure I Indirubin inhibited cell viability in ovarian cancer cells.

Notes: (A) A2780 and OVCAR3 cells were incubated with indirubin at different concentrations (0, 0.5, I, 2, 5, 10, and $20 \mu \mathrm{M})$ for 72 hours. (B, C) A2780 and OVCAR3 cells were exposed to indirubin ( 2 and $5 \mu \mathrm{M}$ ), respectively, for different time points $(0,24,48$, and 72 hours). Cell viability was measured using CCK-8 assays. (D) Colony formation assay of A2780 and OVCAR3 cells was treated with indirubin ( 2 and $5 \mu \mathrm{M})$, respectively. The right panel shows the quantitative results. Each experiment was performed in triplicate independently. The data are presented as mean $\pm S D$. $* P<0.05, * * P<0.01, * * * P<0.001$ vs control group.

Abbreviation: CCK-8, Cell Counting Kit-8. 
A

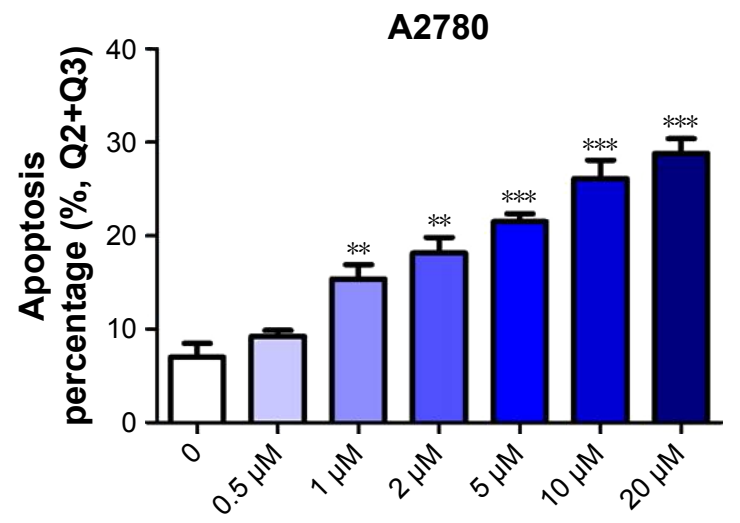

Indirubin

C
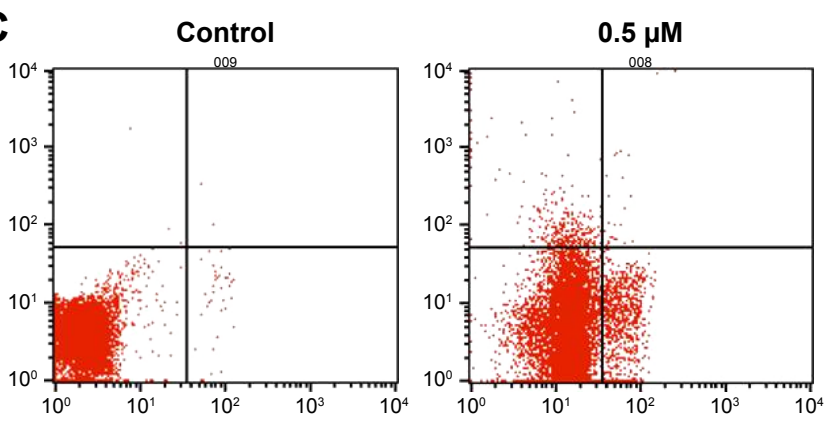

$5 \mu \mathrm{M}$

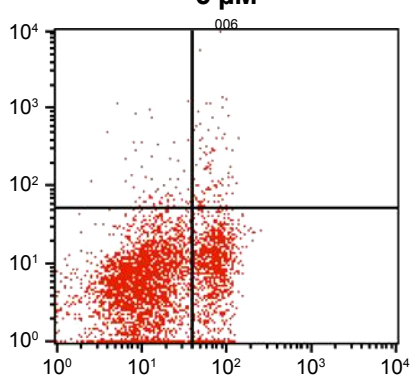

B

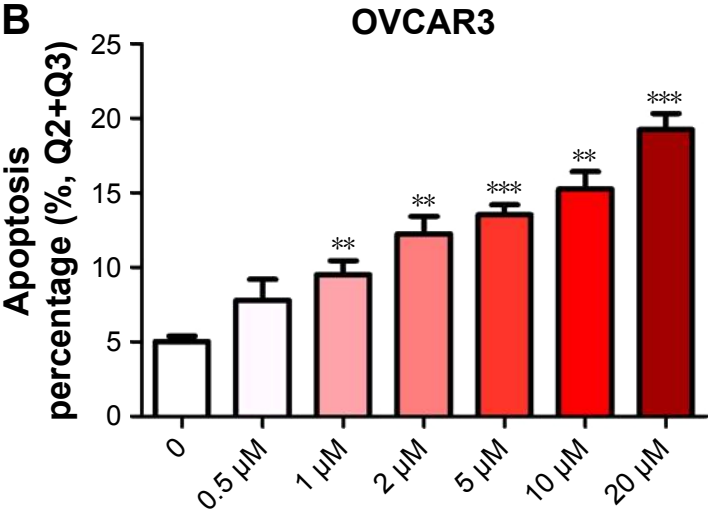

Indirubin
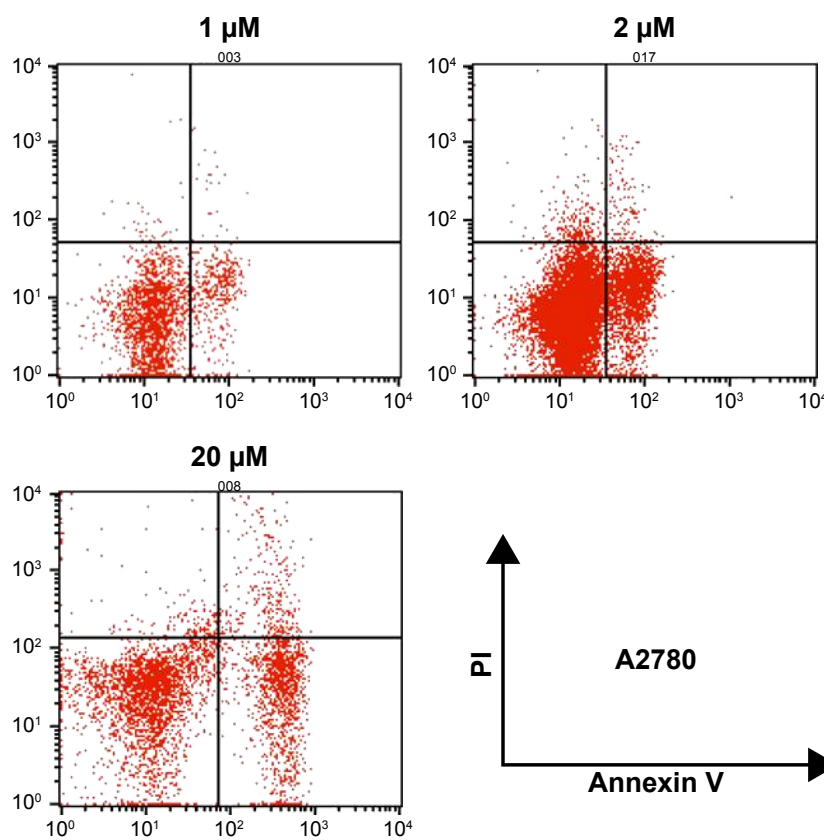

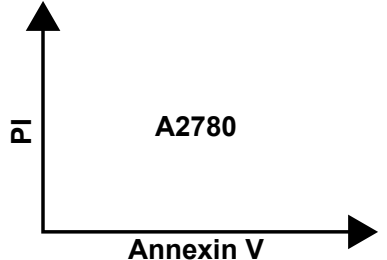

Annexin V

Figure 2 Indirubin induced apoptosis in ovarian cancer cells.

Notes: A2780 (A) and OVCAR3 (B) cells were treated with indirubin at different concentrations (0, 0.5, I, 2, 5, 10, and 20 $\mu$ M) for 72 hours. Flow cytometry analysis showed indirubin induced higher apoptosis with increasing doses of indirubin. (C) Early and late apoptotic events of A2780 cells treated without or with different dose of indirubin were detected by flow cytometry. Top left quadrant indicates non-apoptotic cells; top right quadrant represents late apoptosis events; bottom right quadrant represents early apoptosis cells; and bottom left quadrant represents living cells. Each experiment was performed in triplicate independently. The data are presented as mean $\pm S D$. $* * P<0.01$, $* * * P<0.001$ vs control group.

\section{1, 2, 5, 10, and $20 \mu \mathrm{M}$ ) for 72 hours, Annexin V-labeled cell} apoptosis increased with the increased dosage of indirubin. These results suggested that indirubin treatment induces the apoptosis of ovarian cancer cells in vitro.

\section{Cell viability inhibitory effects of indirubin was associated with the inhibition of STAT3 signaling}

To further explore the molecular mechanism of anti-viability action of indirubin, we investigated the effect of indirubin on the cancer-related STAT3 signaling pathway. We found that indirubin caused downregulation of phospho-STAT3
(Tyr705) dose-dependently in both A2780 and OVCAR3 cells (Figure 3A and B). As is known, STAT3, activated by phosphorylation, plays a key role as a critical transcription activator in cell proliferation. We then analyzed the expression of STAT3 downstream genes. Results showed that indirubin significantly inhibited the expression of Cyclin D1 and C-myc (Figure 3A and B). On the other hand, STAT3 is also involved in the inhibition of apoptosis. Consistently, we found that the pro-apoptosis Bax and cleaved caspase 3 were activated, whereas the anti-apoptotic Bcl-xL was repressed by indirubin in the 2 cell lines dose-dependently (Figure 4A and $\mathrm{B})$. These findings suggested that indirubin exerts 


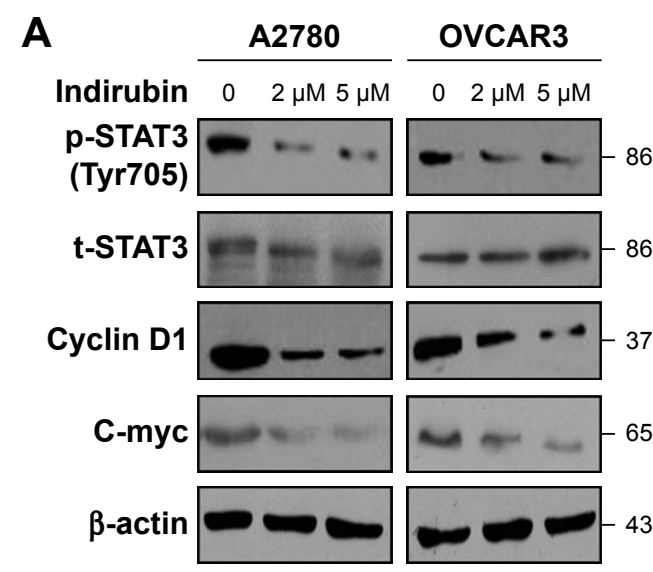

\section{B}

A2780
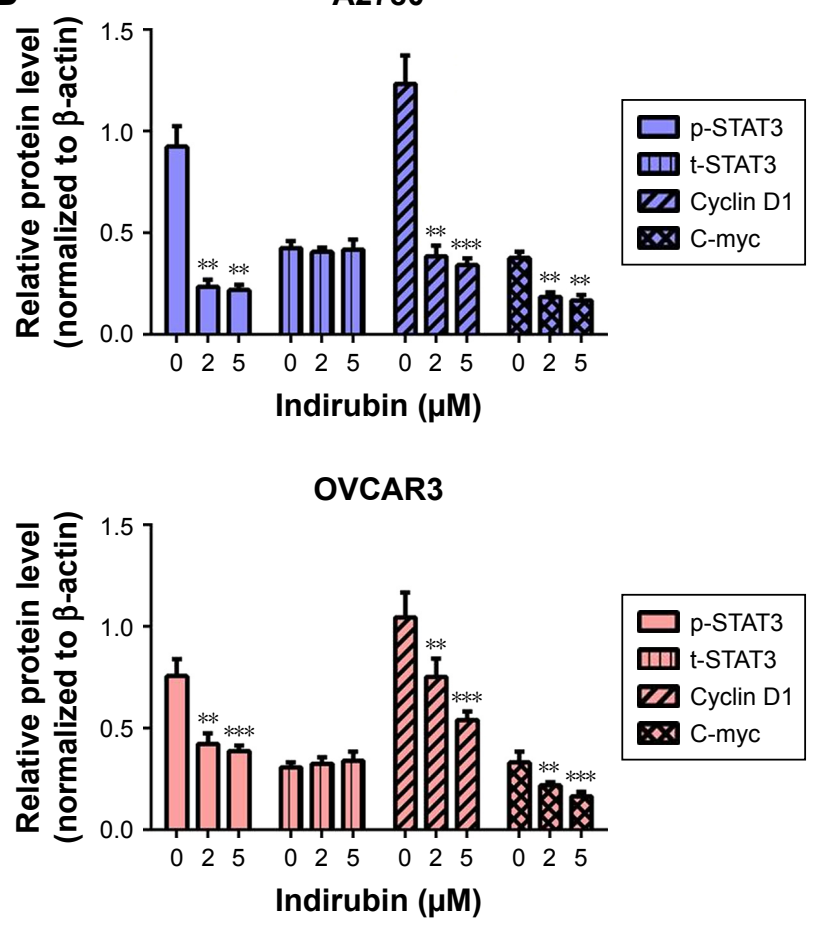

Figure 3 Indirubin-mediated expression of survival-related protein altered.

Notes: (A) Western blot assay showed that indirubin downregulated the phosphorylated level of STAT3 and the expression of survival related protein Cyclin DI, C-myc with increasing concentrations in A2780 and OVCAR3 cells. Each experiment was performed in triplicate independently. (B) Quantitative results shown by Image) software. $* * P<0.01$ I $* * * P<0.001$.

A

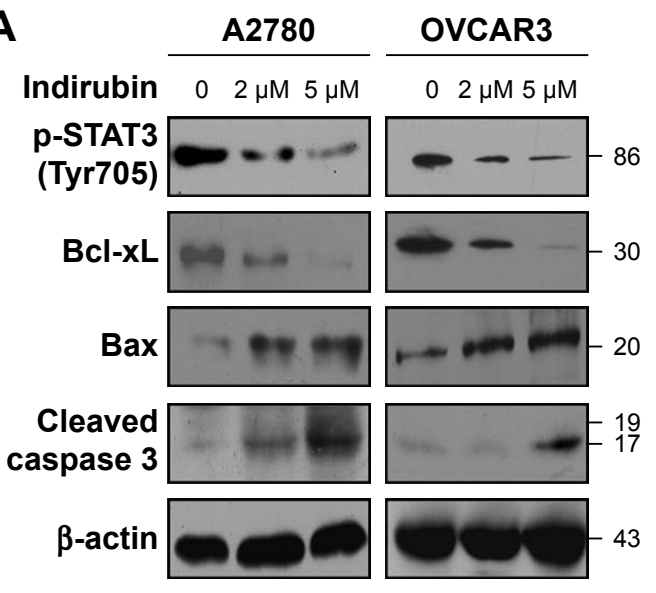

\section{B}
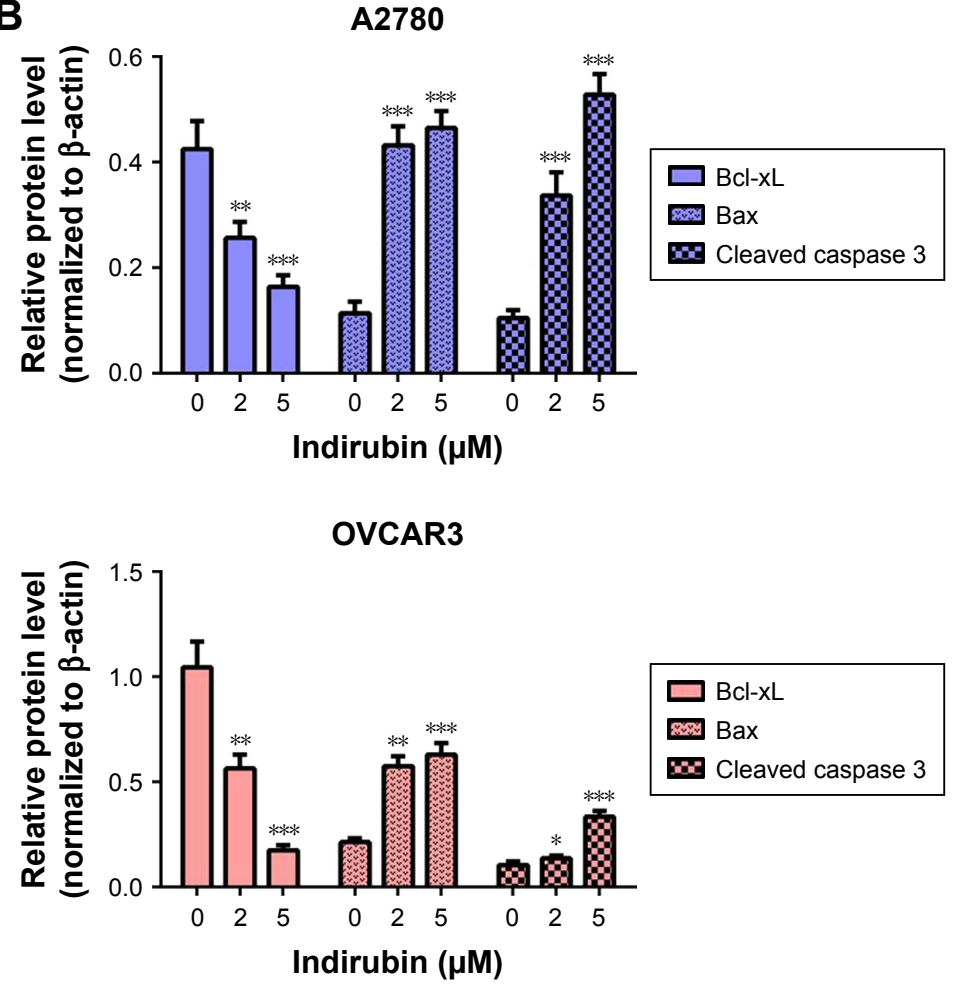

Figure 4 Indirubin-mediated expression of apoptosis-related protein altered.

Notes: (A) Western blot assay showed that indirubin downregulated the expression of anti-apoptosis protein Bcl-xL and upregulated pro-apoptosis protein Bax, cleaved caspase 3 with increasing concentrations in A2780 and OVCAR3 cells. Each experiment was performed in triplicate independently. (B) Quantitative results shown by ImageJ software. $* P<0.05 ; * * P<0.01 ; * * * P<0.001$. 
anti-viability effects by inhibiting the activation of STAT3 signaling.

\section{Colivelin partly reversed the indirubin- induced suppression of cell viability and phosphorylation of STAT3}

To investigate whether indirubin played anti-viability roles through the phosphorylation of STAT3, colivelin, a STAT3 activator, was used in our system. A2780 cells were pretreated with $0.5 \mu \mathrm{M}$ colivelin or dimethyl sulfoxide (DMSO) for 1 hour, followed by treated with or without $5 \mu \mathrm{M}$ indirubin for 72 hours. The Western blot assay results showed that colivelin significantly induced the phosphorylation of STAT3, while indirubin significantly inhibited it. Moreover, we found that pretreatment of colivelin could partly reverse the indirubin-induced suppression of STAT3 phosphorylation (Figure 5A). Next, flow cytometry assay showed that colivelin also reversed the cell apoptosis phenotype induced by indirubin (Figure 5B). In order to make our conclusion more solid, we repeated the treatment in OVCAR3 cells (Figure 5C). CCK-8 assay showed that cell viability inhibition induced by indirubin was significantly impaired by pretreatment of colivelin (Figure 5D). Overall, these results suggested that indirubin exerts anti-viability effects partly through the activation of STAT3 signaling pathway.

\section{Discussion}

As an active component of the traditional Chinese herbal medicine, Danggui Longhui Wan, indirubin is known for treatment of chronic myelogenous leukemia. ${ }^{9}$ Besides, recent studies demonstrate that indirubin as well as its derivatives act as potent inhibitors against CDKs and display potent growth inhibitory effects in human cancer cells. ${ }^{16,17}$ Specifically, indirubin inhibits the proliferation of a wide range of cancer cells, for example, lung cancer cell lines A549 and LXFL529L, breast cancer cell line MCF-7, prostate cancer
A

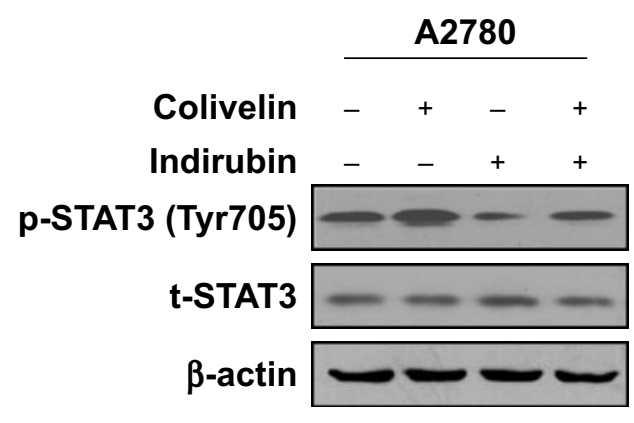

C

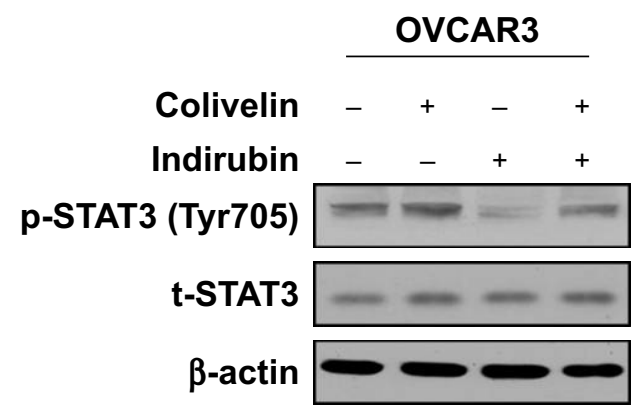

B

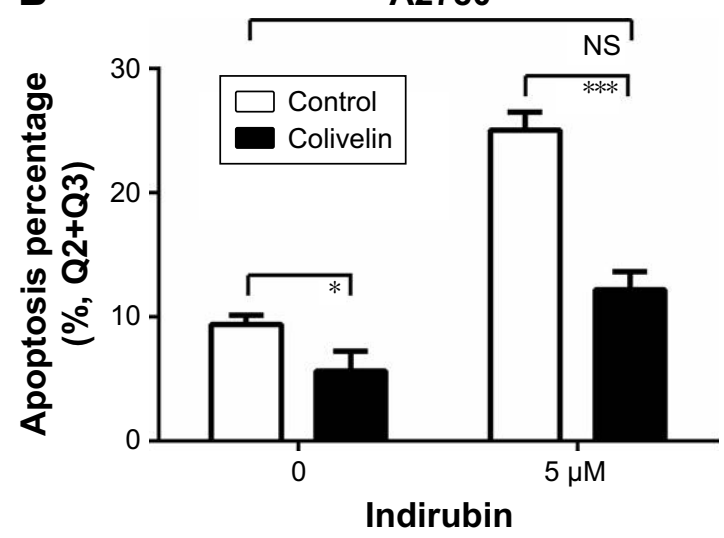

D

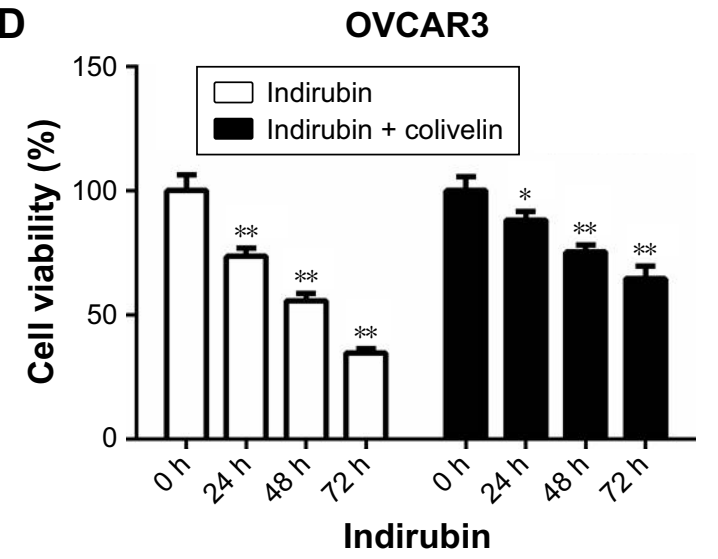

Figure 5 Colivelin could partly reverse the indirubin-induced suppression of cell proliferation and phosphorylation of Stat3.

Notes: (A) A2780 cells were pretreated with $0.5 \mu$ M colivelin (Stat3 activator) or DMSO for I hour and followed by treatment with or without $5 \mu$ M indirubin. Seventytwo hours later, the cells were harvested for Western blot assay. (B) A2780 cells were pretreated with $0.5 \mu$ M colivelin or DMSO for I hour and followed by treatment with or without $5 \mu \mathrm{M}$ indirubin. Seventy-two hours later, the cells were harvested for flow cytometry analysis. (C) OVCAR3 cells were pretreated with $0.5 \mu \mathrm{M}$ colivelin or DMSO for I hour and followed by treatment with or without $5 \mu$ M indirubin. Seventy-two hours later, the cells were harvested for Western blot assay. (D) OVCAR3 cells were exposed to $5 \mu \mathrm{M}$ indirubin with or without $0.5 \mu \mathrm{M}$ colivelin for 72 hours. Cell viability was measured by CCK- 8 assays. The data are presented as mean \pm SD. $* P<0.05$, $* * P<0.0$ I, $* * * P<0.00$ I vs control group.

Abbreviation: NS, not significant. 
cell line PC-12, and leukemic cell line K-562. ${ }^{10,11,16,18}$ Among most of these cell lines, indirubin inhibited cells proliferation in a dose-dependent manner. Induction of cell apoptosis could also be caused by arresting of cell cycle in the G1/S or G2/M by indirubin. ${ }^{10,17}$ It remains unclear if other mechanisms exist for explaining the apoptosis induction by indirubin.

Liu et al reported the anti-survival effect of MLS-2384 (a new 6-bromoindirubin derivative) on variant cancer cells, including ovarian cancers. ${ }^{19}$ Yu et al demonstrated an inhibitory effect of (2Z, 3E)-6-bromoindirubin-3'-oxime (a bromoindirubin derivative, known as "BIO") on cell proliferation, cell cycle, migration, and invasion in ovarian cancer cells..$^{20}$ In the present study, we conducted experiments on 2 different ovarian cancer cell lines. Our results showed that simple indirubin significantly inhibited cell viability and induced apoptosis in ovarian cancer cells. Detailed mechanism studies revealed that indirubin repressed the expression of phosphorylated-STAT3, thus repressing the downstream pro-survival proteins and elevating pro-apoptosis ones. Mechanistic studies by using STAT3 activator showed that indirubin exerts anti-viability effects partly through activation of STAT3 signaling pathway.

As is known, signal transducer and activator of transcription (STAT) proteins play an important role in cancer cell survival. ${ }^{21,22}$ Among the protein family members, STAT3 is often constitutively activated in many human cancer cells, and has been implicated as a promising target for cancer therapy. ${ }^{21}$ Its persistent signaling significantly contributes to oncogenesis by promoting cell proliferation and preventing apoptosis. ${ }^{22}$ STAT3 activates tumorigenesis through directly upregulating of genes encoding apoptosis inhibitors and cell cycle regulators like Bcl-xL, Cyclin D1, and C-myc. ${ }^{21,22}$ The link between indirubin and STAT3 activation has also been discovered by several other groups previously. ${ }^{23-25}$

\section{Conclusion}

Our study provided solid evidence for anti-survival activity of indirubin by inhibiting cell viability and inducing apoptosis in human ovarian cancer cells, which involved impaired STAT3 signaling. Therefore, indirubin is a potent inhibitor of the STAT3 signaling and can serve as a potential drug candidate against human ovarian cancer.

\section{Disclosure}

The authors report no conflicts of interest in this work.

\section{References}

1. Knutson KL, Karyampudi L, Lamichhane P, Preston C. Targeted immune therapy of ovarian cancer. Cancer Metastasis Rev. 2015;34(1): $53-74$.
2. Torre LA, Bray F, Siegel RL, et al. Global cancer statistics, 2012. CA Cancer J Clin. 2015;65(2):87-108.

3. Au KK, Josahkian JA, Francis JA, Squire JA, Koti M. Current state of biomarkers in ovarian cancer prognosis. Future Oncol. 2015;11(23): 3187-3195.

4. He QZ, Luo XZ, Wang K, et al. Isolation and characterization of cancer stem cells from high-grade serous ovarian carcinomas. Cell Physiol Biochem. 2014;33(1):173-184.

5. Vaughan S, Coward JI, Bast RC, et al. Rethinking ovarian cancer: recommendations for improving outcomes. Nat Rev Cancer. 2011; 11(10):719-725.

6. Graham JG, Quinn ML, Fabricant DS, Farnsworth NR. Plants used against cancer - an extension of the work of Jonathan Hartwell. J Ethno pharmacol. 2000;73(3):347-377.

7. Newman DJ, Cragg GM. Natural products as sources of new drugs over the 30 years from 1981 to 2010. J Nat Prod. 2012;75(3):311-335.

8. Yang G, Li X, Li X, et al. Traditional chinese medicine in cancer care: a review of case series published in the chinese literature. Evid Based Complement Alternat Med. 2012;2012:751046.

9. Xiao Z, Hao Y, Liu B, Qian L. Indirubin and meisoindigo in the treatment of chronic myelogenous leukemia in China. Leuk Lymphoma. 2002;43(9):1763-1768.

10. Hoessel R, Leclerc S, Endicott JA, et al. Indirubin, the active constituent of a Chinese antileukaemia medicine, inhibits cyclin-dependent kinases. Nat Cell Biol. 1999;1(1):60-67.

11. Eisenbrand G, Hippe F, Jakobs S, Muehlbeyer S. Molecular mechanisms of indirubin and its derivatives: novel anticancer molecules with their origin in traditional Chinese phytomedicine. J Cancer Res Clin Oncol. 2004;130(11):627-635.

12. Cheng X, Merz KH, Vatter S, et al. Identification of a Water-Soluble Indirubin Derivative as Potent Inhibitor of Insulin-like Growth Factor 1 Receptor through Structural Modification of the Parent Natural Molecule. J Med Chem. 2017;60(12):4949-4962.

13. Nam S, Wen W, Schroeder A, et al. Dual inhibition of Janus and Src family kinases by novel indirubin derivative blocks constitutivelyactivated Stat3 signaling associated with apoptosis of human pancreatic cancer cells. Mol Oncol. 2013;7(3):369-378.

14. Tsakiri EN, Gaboriaud-Kolar N, Iliaki KK, et al. The Indirubin Derivative 6-Bromoindirubin-3'-Oxime Activates Proteostatic Modules, Reprograms Cellular Bioenergetic Pathways, and Exerts Antiaging Effects. Antioxid Redox Signal. 2017;27(14):1027-1047.

15. Jie $\mathrm{C}$, Luo Z, Chen $\mathrm{H}$, et al. Indirubin, a bisindole alkaloid from Isatis indigotica, reduces $\mathrm{H} 1 \mathrm{~N} 1$ susceptibility in stressed mice by regulating MAVS signaling. Oncotarget. 2017;8(62):105615-105629.

16. Marko D, Schätzle S, Friedel A, et al. Inhibition of cyclin-dependent kinase $1(\mathrm{CDK} 1)$ by indirubin derivatives in human tumour cells. $\mathrm{Br} J$ Cancer. 2001;84(2):283-289.

17. Leclerc S, Garnier M, Hoessel R, et al. Indirubins inhibit glycogen synthase kinase- 3 beta and CDK5/p25, two protein kinases involved in abnormal tau phosphorylation in Alzheimer's disease. A property common to most cyclin-dependent kinase inhibitors? J Biol Chem. 200(276):251-260.

18. Damiens E, Baratte B, Marie D, Eisenbrand G, Meijer L. Anti-mitotic properties of indirubin-3'-monoxime, a CDK/GSK-3 inhibitor: induction of endoreplication following prophase arrest. Oncogene. 2001; 20(29):3786-3797.

19. Liu L, Gaboriaud N, Vougogianopoulou K, et al. MLS-2384, a new 6-bromoindirubin derivative with dual JAK/Src kinase inhibitory activity, suppresses growth of diverse cancer cells. Cancer Biol Ther. 2014;15(2):178-184.

20. Yu AS, Zhao L. Effects of the GSK-3 $\beta$ inhibitor (2Z,3E)-6bromoindirubin-3'-oxime upon ovarian cancer cells. Tumour Biol. 2016;37(4):4857-4864.

21. Yu H, Jove R. The STATs of cancer - new molecular targets come of age. Nat Rev Cancer. 2004;4(2):97-105.

22. Buettner R, Mora LB, Jove R. Activated STAT signaling in human tumors provides novel molecular targets for therapeutic intervention. Clin Cancer Res. 2002;8(4):945-954. 
23. Zhang $\mathrm{X}$, Song $\mathrm{Y}, \mathrm{Wu} \mathrm{Y}$, et al. Indirubin inhibits tumor growth by antitumor angiogenesis via blocking VEGFR2-mediated JAK/STAT3 signaling in endothelial cell. Int J Cancer. 2011;129(10):2502-2511.

24. Nam S, Buettner R, Turkson J, et al. Indirubin derivatives inhibit Stat3 signaling and induce apoptosis in human cancer cells. Proc Natl Acad Sci U S A. 2005;102(17):5998-6003.
25. Schwaiberger AV, Heiss EH, Cabaravdic M, et al. Indirubin-3'monoxime blocks vascular smooth muscle cell proliferation by inhibition of signal transducer and activator of transcription 3 signaling and reduces neointima formation in vivo. Arterioscler Thromb Vasc Biol. 2010;30(12):2475-2481.

\section{Publish your work in this journal}

Drug Design, Development and Therapy is an international, peerreviewed open-access journal that spans the spectrum of drug design and development through to clinical applications. Clinical outcomes, patient safety, and programs for the development and effective, safe, and sustained use of medicines are the features of the journal, which has also been accepted for indexing on PubMed Central. The manuscript management system is completely online and includes a very quick and fair peer-review system, which is all easy to use. Visit http://www.dovepress.com/testimonials.php to read real quotes from published authors.

Submit your manuscript here: http://www.dovepress.com/drug-design-development-and-therapy-journal 